\title{
Computação Desplugada na UDESC Portas Abertas
}

\author{
Cristiani Crema, Katiane K. G. Krause, Isabela Gasparini, Avanilde Kemczinski \\ PPGECMT, PPGCA, UDESC - Universidade do Estado de Santa Catarina \\ \{cristiani.crema, kati.kazuza\}@gmail.com, \{isabela.gasparini,avanilde.kemczinski\}@udesc.br
}

\begin{abstract}
Resumo: Este artigo apresenta o planejamento, execução e análise de uma experiência na aplicação de atividades desplugadas realizadas no dia em que a universidade abre suas Portas para estudantes do Ensino Médio vivenciarem o mundo acadêmico. O objetivo deste estudo foi estimular o Pensamento Computacional de forma colaborativa por meio de atividades desplugadas ensinando conceitos relacionados à ciência da computação de forma divertida e interativa. Como resultado verificou-se a percepção dos estudantes com relação ao interesse, associação com o pensamento computacional e a área de ciência da computação.
\end{abstract}

Palavras-chave: Computação Desplugada. Pensamento Computacional. Ensino Médio.

\section{Unplugged Computing at UDESC Open Doors}

Abstract: This paper presents the planning, execution and analysis of an experience in the application of computer science unplugged activities carried out on the day that the university is opened for high school students to experience the academic world. The purpose of this study was to stimulate Computational Thinking in a collaborative way through unplugged activities concepts related to computer science in a fun and interactive way. As a result, the students' perception regarding interest, association with computational thinking and the area of computer science was verified.

Keywords: Unplugged Computing. Computational thinking. High School.

\section{Introdução}

Compreender as engrenagens lógicas que envolvem a execução de ações computacionais nem sempre é uma tarefa simples, considerando seu alto grau de abstração. No entanto, o processo de construção do pensamento lógico, organizado e associativo pode ser iniciado e exercitado por meio de atividades concretas, desafiadoras e divertidas que simulam operações computacionais (MANHÃES et al, 2017).

A Computação Desplugada tem o objetivo de ensinar os fundamentos sobre a Ciência da Computação sem o uso do computador (BELL et al, 2011), possibilitando tornar concreto conceitos como números binários, algoritmos, memória, bancos de dados e ordenação (MARTINHAGO et al, 2014); desenvolver o pensamento computacional e tornar mais eficiente a resolução de tarefas cognitivas (BLIKSTEIN, 2008). Além disso, enquanto método de ensino, possibilita desenvolver habilidades de resolução de problemas, criatividade e trabalho em equipe (SILVA et al., 2014), sendo indicada inclusive para crianças (BORDINI et al, 2016). Outra vantagem deste método é sua adaptabilidade a locais que não dispõem de infraestrutura e recursos financeiros, visto que as atividades não necessitam da utilização de energia elétrica, hardware ou software (SILVA et al, 2014).

No trabalho de Bezerra (2014) foram realizadas atividades desplugadas por acadêmicos de Licenciatura em Ciência da Computação que estavam cursando a disciplina de "Introdução à Computação". Os acadêmicos organizaram uma gincana que foi realizada em uma escola que funciona dentro da própria universidade, na qual teve a participação de 19 alunos do Ensino Médio. As atividades desplugadas aplicadas baseadas no livro de Bell et al. (2011) foram: contando os pontos (números binários), colorindo os números (representação de imagem), você pode repetir? (compreensão de texto), a mágica de virar cartas (detecção de erros) e vinte palpites (teoria da informação). Após a realização das atividades os acadêmicos aplicaram um questionário para saber o nível de satisfação dos participantes das atividades realizadas. 
Como resultado o autor destaca a oportunidade que os alunos da computação tiveram em vivenciar experiência em sala de aula e dos alunos da escola de aprenderem conceitos de computação de forma divertida.

Vieira, Passos e Barreto (2013), descreve o relato de um projeto de teatro realizado por dez acadêmicos dos cursos: Ciência da Computação, Sistemas de Informação e Engenharia de Software, que teve como objetivo ensinar fundamentos da Ciência da Computação aos alunos de escolas públicas usando computação desplugada. A peça foi apresentada em quatro escolas públicas, sendo três estaduais e uma municipal. O público-alvo foram alunos de Ensino Fundamental (a partir do $8^{\circ}$ ano) e do Ensino Médio ( $1^{\circ}$ e $2^{\circ}$ série). Seis peças teatrais interativas foram realizadas, com as seguintes atividades desplugadas: a mágica de virar as cartas (detecção de erros), transmitindo uma mensagem com segurança (criptografia), contando os pontos (números binários), colorindo com números (representação de imagens), o jogo da laranja (bloqueios nas redes) e vamos dançar? (ordenação). No final da apresentação os autores realizaram um questionário de satisfação com os alunos que assistiram à peça, no qual evidenciaram que a maioria dos alunos gostaram das atividades e demonstraram interesse pela área de computação.

O livro Computer Science Unplugged (Bell et al., 2011) apresenta atividades práticas desplugadas para crianças a partir dos 7 anos de idade. Seu material foi construído visando suprir as dificuldades encontradas no ensino de conceitos computacionais. Esse livro contempla doze atividades desplugadas, sendo dividido em três partes: representando as informações, algoritmos e representando procedimentos. O livro é comumente utilizado como fonte de inspiração para a criação de novas atividades de computação desplugada. Este artigo apresenta o planejamento, execução e análise de uma experiência na aplicação de atividades desplugadas realizadas com estudantes do Ensino Médio e analisa a percepção dos estudantes com relação ao interesse, associação com o pensamento computacional e a área de ciência da computação. Para tal, a seção 2 descreve o design da pesquisa, os resultados são apresentados na seção 3 e sua discussão na seção 4, finalizando com as considerações deste trabalho.

\section{Design da pesquisa}

Nessa etapa caracteriza-se os participantes, a seleção e confecção das atividades e o planejamento e condução de aplicação das atividades realizadas da pesquisa. Este trabalho foi planejado para ser aplicado no evento "Udesc Portas Abertas" (UPA). O UPA é uma ação semestral direcionada aos estudantes do Ensino Médio ( $2^{\mathrm{a}}$ e $3^{\mathrm{a}}$ séries) de escolas públicas e privadas que oportuniza a aproximação desses estudantes com a comunidade universitária, por meio de visitação e interação nos projetos e atividades desenvolvidas pelos cursos de graduação, projetos de pesquisa e de extensão; vivência de experimentos nos laboratórios e conversas com os acadêmicos.

O evento é organizado e realizado pela Direção de Extensão com o apoio dos departamentos, grupos de pesquisa e extensão e de acadêmicos voluntários, funcionários e professores; possui a duração de um dia, com tempo estimado de visitação a cada ação da universidade entre 15 a 20 minutos para cada interação e roteiro pré-definido, num tempo total estimado de 3 horas por turno. Os grupos são acompanhados por guias (acadêmicos voluntários) e professores (das turmas visitantes), podendo conter até 60 alunos. Neste semestre (2019/01) o evento contou com mais de 900 estudantes no campus. Deste total, 129 estudantes de 6 escolas participaram da ação de computação desplugada descrita neste trabalho. Vale ressaltar que a aplicação das atividades com os estudantes neste experimento seguiu as diretrizes 
do Comitê de Ética e Pesquisa com Seres Humanos e a aceitação do Termo de Consentimento Livre e Esclarecido.

\subsection{Seleção e confecção das atividades}

A seleção das atividades desplugadas aplicadas baseou-se nos critérios de tempo de realização estimado (limitado pela dinâmica do evento UPA), perfil do estudante (ensino médio), ser colaborativa, dinâmica, atrativa e a facilidade de adaptação, visto que o número de estudantes por experimento não pôde ser previamente determinado. Para definir quais e quantas atividades seriam aplicadas daquelas selecionadas pelos critérios, foi executado um teste piloto com 9 pessoas, para estimar o tempo médio requerido em cada atividade, tempo de resposta do questionário e tempo para apresentação de proposta e organização dos estudantes. O teste piloto retornou três atividades: algoritmo de ordenação, colorindo os números e decodificando a mensagem, que foram escolhidas para a realização do UPA.

\subsubsection{Algoritmo de ordenação}

Um algoritmo consiste numa sequência de passos descritos que visam atingir um objetivo bem definido, podendo também ser escrito em linguagem natural (ASCENCIO e CAMPOS, 2005). Assim, ao descrever por meio de narrativa a sequência de passos para resolver um problema (por exemplo, cozinhar um bolo, realizar um cálculo ou ligar o computador) o estudante necessita analisar a tarefa, sintetizar e ordenar as etapas tal qual um algoritmo computacional, com a diferença que o estudante não necessitará fazer cálculos funcionais para resolver o problema. Este tipo de atividade foi descrito por Barbosa et al. (2015) em um relato de experiência de uma gincana desplugada realizada numa atividade em que solicitaram aos estudantes do Ensino Médio que descrevessem as etapas de preparação de macarrão instantâneo (miojo).

Com base nessa configuração, desenhou-se a atividade de ordenação narrativa, segmentada em dez passos (frases), referente ao processo de fritar um ovo. Construiuse uma base para anexar à resposta em cartolina (Figura 1a) e um envelope contendo dez fitas aleatórias (frases) com os passos descritos (Figura 1b):

Pegar um ovo; Quebrar o ovo em um recipiente testando se ele está ou não estragado; Colocar óleo em uma frigideira; Acender o fogo; Colocar a frigideira no fogo; Esperar até o óleo ficar quente; Colocar o ovo na frigideira quente e colocar o sal; Manusear com uma espátula o ovo até que esteja totalmente frito; Desligar o fogo e tirar o ovo da frigideira e Colocar o ovo no prato e servir.
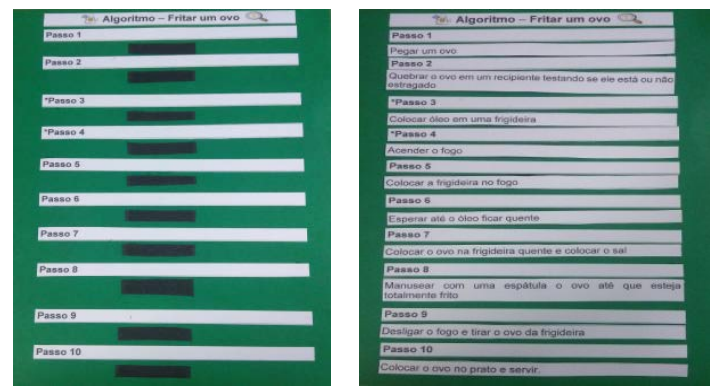

Figura 1. Atividade de algoritmo de ordenação "Fritar um ovo" - da esquerda para direita, (a) gabarito para resposta, (b) frases com os passos.

A atividade proposta consiste em anexar na ficha de resposta a ordem para a realização da tarefa. Para simular o processo realizado pelo computador, colocou-se tiras de velcro (fixador), de tal forma que na percepção de erro pelo aluno, toda base de resposta 
abaixo do erro deveria ser reordenada. O tempo estimado para realização da atividade “Ordenação de Algoritmo” é de aproximadamente 2 minutos.

\subsubsection{Colorindo com Números}

As telas dos computadores são formadas por pequenos pontos chamados pixels, assim, as imagens são transformadas em códigos numéricos que representam quais pontos serão ou não preenchidos (Barreto, 2011). Para compreensão desta transformação, Bell et al (2011) apresenta a codificação resultante da imagem da letra “a” em números (Figura 2a). A primeira linha consiste de um pixel branco (sem preenchimento), seguido de três pixels pretos (com preenchimento) e, por fim, de um pixel branco, retornando o código 131. O primeiro número sempre se refere ao número de pixels brancos. Se o primeiro pixel for preto, a linha começará com um zero. A proposta de Bell et al (2011) da Figura 2a foi adaptada para o experimento, cuja imagem resposta consiste de uma xícara. Aos estudantes, além da explicação, foi entregue uma folha graduada com o respectivo código, que deveria ser convertida em preenchimento (Figura 2b), de acordo com as regras, convertendo assim o código em imagem (Figura 2c). O tempo estimado para realização da atividade "Colorindo os Números” é de aproximadamente 5 minutos.

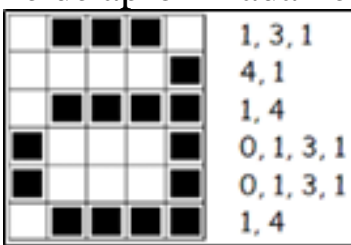

(a)

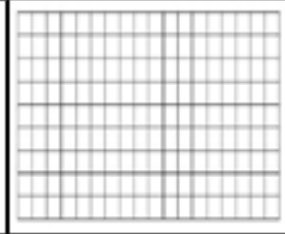

(b)

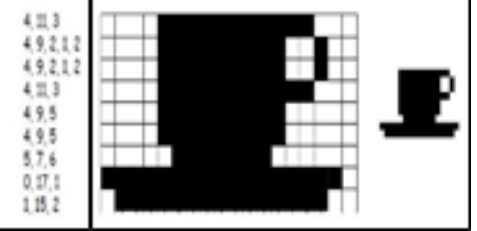

(c)

Figura 2. Atividade desplugada colorindo com números: (a) exemplo de transformação, (b) base da atividade proposta aos estudantes, (c) gabarito da resposta (resultado).

\subsubsection{Decifrando a mensagem}

Segundo Cavalcante (2005), a criptografia trata de um conjunto de técnicas que permite tornar incompreensível uma mensagem originalmente escrita com clareza, de forma a permitir que apenas o destinatário a decifre e compreenda. A criptografia simétrica usa somente uma chave para codificar e decodificar a mensagem e é usada em transmissões de dados cujo nível de segurança não necessita ser elevado. É relativamente rápida, porém, tanto o transmissor quanto o receptor devem conhecer a chave. A atividade Decifrando a Mensagem consistiu nos estudantes decodificarem a mensagem criptografada com chave única (simétrica). Para tal, foi entregue um cartão simulando a tela de uma rede social e a base de caracteres da criptografia (chave) conforme Figura 3. A mensagem decodificada é \#BEM-VINDO(A) A UNIVERSIDADE! O tempo estimado para realização da atividade é de aproximadamente 5 minutos.

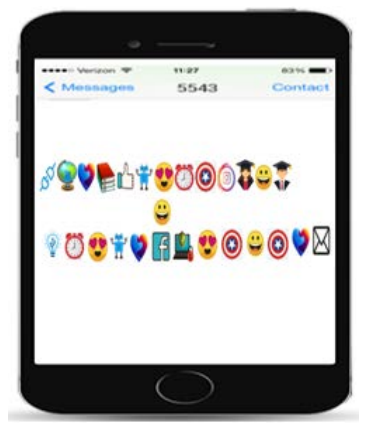

\begin{tabular}{|c|c|c|c|c|c|c|c|c|c|c|c|c|c|c|c|c|c|}
\hline A & & C & D & $E$ & $F$ & G & H & I & $\mathrm{J}$ & K & $L$ & $M$ & & $\mathrm{~N}$ & 0 & $P$ & $Q$ \\
\hline & & $\boldsymbol{W}$ & (†) & & 8 & $\Leftrightarrow$ & 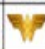 & 2 & 4 & g & Fo & 1 & & (1) & (0) & 8 & \\
\hline$R$ & S & $T$ & U & V & W & $x$ & $Y$ & $z$ & $\theta$ & 1 & 2 & 3 & & 4 & 5 & 6 & 7 \\
\hline$f$ & 0 & (8) & (p) & In & $\therefore$ & 6 & 将 & \{ & in & 88 & $\varepsilon$ & & & 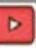 & 8 & & \\
\hline 8 & 9 & $?$ & $!$ & & & : & 1 & 1 & 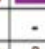 & \# & & & & & & & \\
\hline & & & & & $\theta$ & & $F$ & 학 & a & 10 & & & & & & & \\
\hline
\end{tabular}

Figura 3. Atividade Decodificando a Mensagem - à esquerda a simulação de uma tela de conversa em rede social com a imagem recebida pelo usuário criptografada e à direita a chave para decodificação.

V. $17 \mathrm{~N}^{\mathrm{o}}$ 3, dezembro, 2019 RENOTE DOI: 


\subsection{Planejamento e condução de aplicação das atividades}

Inicialmente, realizou-se uma entrevista com a diretora responsável pelo evento UPA, a fim de compreender a dinâmica do evento, perfil dos estudantes visitantes e possibilidade de aplicação do experimento. Com estes dados, iniciou-se o processo de levantamento e seleção de atividades desplugadas para o Ensino Médio (seção 2.2). Por fim, a definição da dinâmica e condução das atividades foi obtida após brainstorm com membros de um grupo de pesquisa em Informática na Educação da mesma universidade. O experimento foi realizado pelo pesquisador principal, acompanhado de outros seis bolsistas (de graduação e pós-graduação), em uma sala de aula disposta por função, conforme layout da Figura 4.

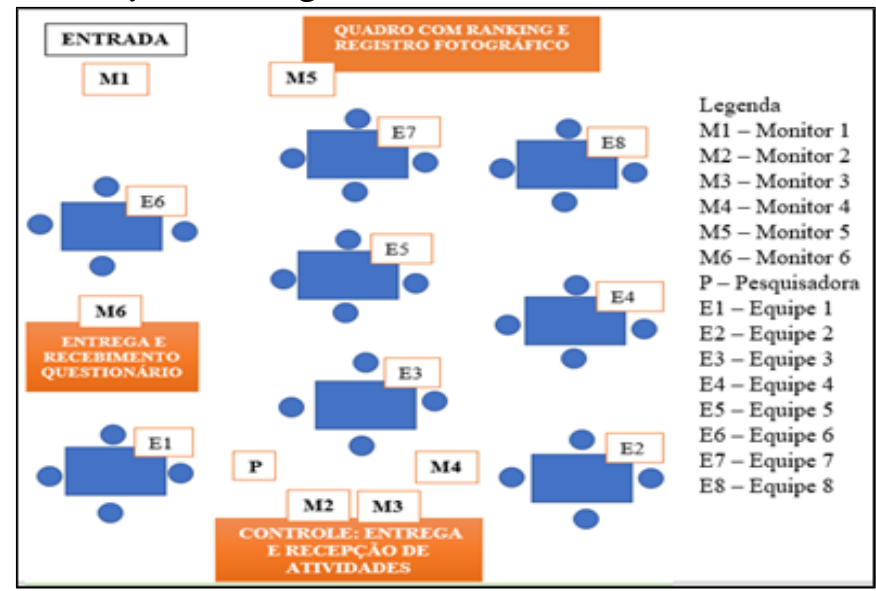

Figura 4 - Layout organizacional e funcional

Os estudantes foram recepcionados pelo monitor M1, que solicitou que os mesmos se reunissem em equipes de sua preferência conforme a organização das cadeiras dispostas na sala de aula. O pesquisador explicou os conceitos e as atividades desplugadas, bem como, a dinâmica que ocorreria às atividades. Em seguida, um membro de cada equipe dirigiu-se ao monitor M3 para retirada da primeira atividade.

Ao término de cada atividade um dos membros de cada equipe retirava a atividade subsequente e os tempos de realização de cada atividade por equipe eram computados pelo monitor M2. O monitor M5 realizou anotação no quadro do ranking geral das equipes e fez o registro fotográfico dos estudantes (com seus consentimentos por meio de um terno adicional para fotografias). O monitor M4 e o pesquisador sanaram as dúvidas, conferiram se as atividades estavam corretas e fizeram anotações observacionais. O monitor M6 teve como função a entrega e o recebimento dos questionários.

As atividades seguiram a ordem "Fritar um ovo" (algoritmo de ordenação), “Colorindo com números” (pixels) e "Decodificando a mensagem” (criptografia). Somente após o término das atividades foi entregue o Questionário de Percepção da Experimentação. Já a proposta do ranking dos tempos totais por equipes foi escolhida como elemento de motivação adicional.

\section{Resultados}

Ao total, cento e vinte nove estudantes do Ensino Médio da $3^{\text {a }}$ Série ( $n=129$, 46,5\% feminino) participaram do experimento, envolvendo alunos de seis escolas. Em relação à idade, 65,1\% possuíam entre 16 e 17 anos, 34,1\% acima de 17 anos e um estudante não informou a idade.

O número de integrantes das equipes variou entre 2 a 8 estudantes. No período matutino, a distribuição das equipes ficou a critério dos alunos, enquanto no período 
vespertino, as ilhas (mesas e cadeiras) foram fixadas para no máximo quatro integrantes. Esta distribuição foi importante para a análise qualitativa da dinâmica entre os grupos. Observou-se que a disposição fixada (máximo quatro alunos por equipe) apresentou maior interação entre os membros, tomada de decisão mais eficiente (tempo) e baixa quantidade de estudantes ociosos (diferentemente das equipes com muitos integrantes). O Quadro 1 apresenta o desempenho das equipes participantes do UPA. Vale ressaltar que a escola \#2 pode participar somente de uma atividade, visto que os estudantes chegaram atrasados na sala, e deveriam sair mais cedo, para cumprirem todo o trajeto pelos grupos e projetos da universidade.

\begin{tabular}{|c|c|c|c|c|c|c|c|}
\hline \# & $\begin{array}{c}\text { Perfil da } \\
\text { Escola }\end{array}$ & $\begin{array}{l}\text { Turno de } \\
\text { visitação }\end{array}$ & $\begin{array}{c}\text { Nome da } \\
\text { equipe }\end{array}$ & $\begin{array}{c}\mathbf{N}^{\mathbf{o}} \text { de } \\
\text { integrantes }\end{array}$ & $\begin{array}{l}\text { Atividades } \\
\text { realizadas } \\
(\text { máx } n=3)\end{array}$ & $\begin{array}{l}\text { Tempo total } \\
\text { por equipe }\end{array}$ & $\begin{array}{c}\text { Tempo } \\
\text { médio das } \\
\text { equipes }\end{array}$ \\
\hline \multirow{5}{*}{1} & \multirow{6}{*}{ 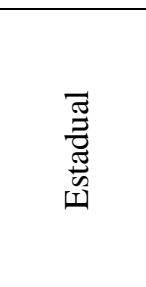 } & \multirow{6}{*}{ 兽 } & Equipe 1 & 4 & 3 & 10 minutos & \multirow{6}{*}{$\begin{array}{c}\mathbf{t}=\mathbf{1 3 , 6} \\
\mathbf{m i n} \\
(\mathrm{n}=3, \\
\text { quantidade } \\
\text { de } \\
\text { integrantes } \\
\text { aleatória })\end{array}$} \\
\hline & & & Equipe 2 & 7 & 3 & 10 minutos & \\
\hline & & & Equipe 3 & 8 & 3 & 24 minutos & \\
\hline & & & Equipe 4 & 4 & 3 & 15 minutos & \\
\hline & & & Equipe 5 & 5 & 3 & 11 minutos & \\
\hline & & & Equipe 6 & 2 & 3 & 12 minutos & \\
\hline \multirow{7}{*}{2} & \multirow{7}{*}{ 胥 } & \multirow{7}{*}{ 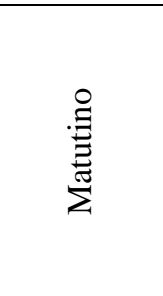 } & Equipe 1 & 5 & 1 & 2 minutos & \multirow{7}{*}{$\begin{array}{c}\mathbf{t}=\mathbf{3 , 3} \mathbf{~ m i n} \\
(\mathrm{n}=1, \\
\text { quantidade } \\
\text { de } \\
\text { integrantes } \\
\text { aleatória) }\end{array}$} \\
\hline & & & Equipe 2 & 3 & 1 & 2 minutos & \\
\hline & & & Equipe 3 & 2 & 1 & 3 minutos & \\
\hline & & & Equipe 4 & 6 & 1 & 3 minutos & \\
\hline & & & Equipe 5 & 5 & 1 & 4 minutos & \\
\hline & & & Equipe 6 & 7 & 1 & 5 minutos & \\
\hline & & & Equipe 7 & 2 & 1 & 4 minutos & \\
\hline \multirow{5}{*}{3} & \multirow{5}{*}{ 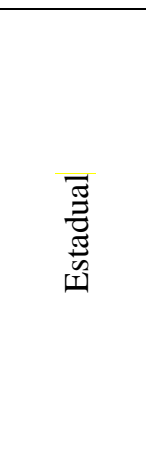 } & \multirow{5}{*}{ 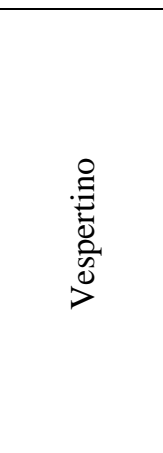 } & Equipe 1 & 3 & 3 & $\begin{array}{l}9 \text { minutos e } \\
11 \text { segundos }\end{array}$ & \multirow{5}{*}{$\begin{array}{c}\mathbf{t}=\mathbf{1 0 , 2} \\
\text { min } \\
(\mathrm{n}=3, \\
\text { quantidade } \\
\text { de } \\
\text { integrantes } \\
\text { fixada })\end{array}$} \\
\hline & & & Equipe 2 & 4 & 3 & $\begin{array}{l}12 \text { minutos e } \\
1 \text { segundo }\end{array}$ & \\
\hline & & & Equipe 3 & 4 & 3 & $\begin{array}{c}11 \text { minutos } \\
\text { e } 11 \\
\text { segundos }\end{array}$ & \\
\hline & & & Equipe 4 & 4 & 3 & $\begin{array}{l}8 \text { minutos e } \\
21 \text { segundos }\end{array}$ & \\
\hline & & & Equipe 5 & 4 & 3 & $\begin{array}{l}10 \text { minutos e } \\
16 \text { segundos }\end{array}$ & \\
\hline \multirow{5}{*}{4} & \multirow{5}{*}{ 预 } & \multirow{5}{*}{ 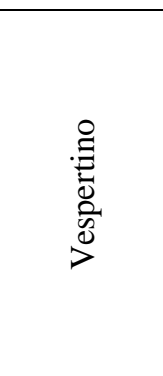 } & Equipe 1 & 4 & 3 & $\begin{array}{c}14 \text { minutos } \\
\text { e } 5 \\
\text { segundos }\end{array}$ & \multirow{5}{*}{$\begin{array}{c}\mathbf{t}=\mathbf{1 1 , 2} \\
\mathbf{m i n} \\
(\mathrm{n}=3, \\
\text { quantidade } \\
\text { de } \\
\text { integrantes } \\
\text { fixada) }\end{array}$} \\
\hline & & & Equipe 2 & 4 & 3 & $\begin{array}{l}10 \text { minutos e } \\
25 \text { segundos }\end{array}$ & \\
\hline & & & Equipe 3 & 4 & 3 & 7 minutos & \\
\hline & & & Equipe 4 & 4 & 3 & $\begin{array}{l}12 \text { minutos e } \\
25 \text { segundos }\end{array}$ & \\
\hline & & & Equipe 5 & 4 & 3 & 12 minutos & \\
\hline \multirow[b]{3}{*}{5} & \multirow{3}{*}{ 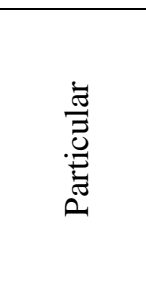 } & \multirow{3}{*}{ 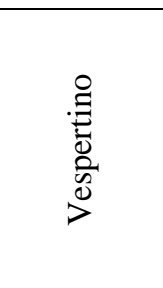 } & Equipe 1 & 4 & 3 & 9 minutos & \multirow{3}{*}{$\begin{array}{c}\mathbf{t}=\mathbf{1 1 , 2} \\
\mathbf{m i n} \\
(\mathrm{n}=3, \\
\text { quantidade } \\
\text { de } \\
\text { integrantes } \\
\text { fixada) }\end{array}$} \\
\hline & & & Equipe 2 & 4 & 3 & $\begin{array}{l}9 \text { minutos e } \\
5 \text { segundos }\end{array}$ & \\
\hline & & & Equipe 3 & 2 & 3 & $\begin{array}{l}15 \text { minutos } \\
25 \text { segundos }\end{array}$ & \\
\hline \multirow{2}{*}{6} & \multirow{2}{*}{ 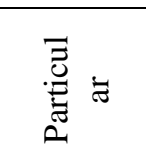 } & \multirow{2}{*}{ 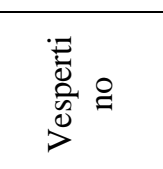 } & Equipe 1 & 4 & 3 & $\begin{array}{l}5 \text { minutos e } \\
25 \text { segundos }\end{array}$ & \multirow{2}{*}{$\begin{array}{c}\mathrm{t}=6,8 \mathrm{~min} \\
(\mathrm{n}=3, \\
\text { quantidade } \\
\text { de }\end{array}$} \\
\hline & & & Equipe 2 & 2 & 3 & $\begin{array}{l}6 \text { minutos e } \\
10 \text { segundos }\end{array}$ & \\
\hline
\end{tabular}




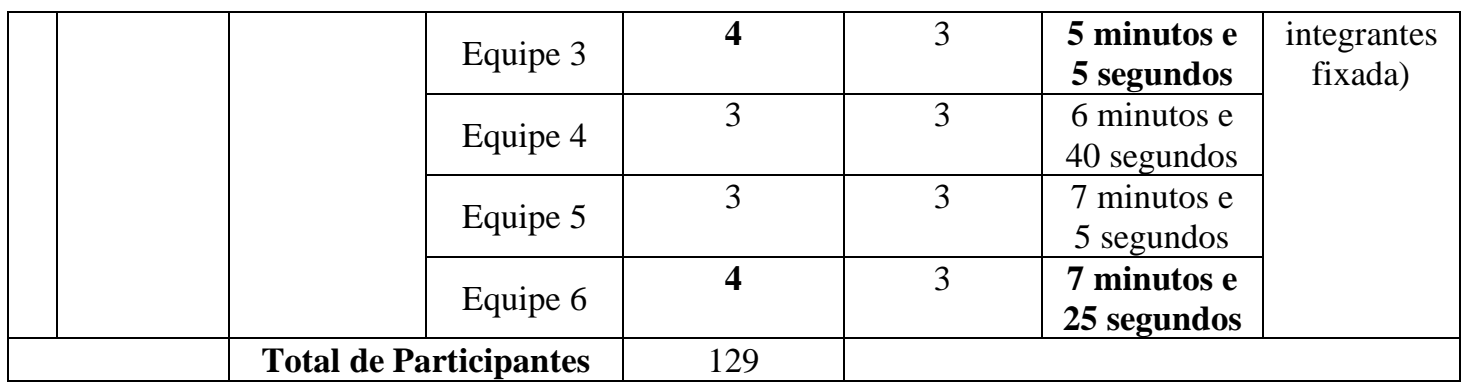

Quadro 1. Desempenho dos alunos nas atividades

Dos cento e vinte nove participantes do experimento, 94,5\% ( $\mathrm{n}=122)$ responderam o Questionário de Percepção da Experiência. Os sete estudantes que não responderam ao questionário não o fizeram por esgotamento do tempo (rodízio dos grupos no evento).

Ao questionar os estudantes sobre predileção nas disciplinas cursadas na escola (Figura 5) os estudantes poderiam marcar mais de uma opção, e ainda no campo "outros" escrever disciplinas adicionais. Observa-se que a disciplina de Matemática está em $4^{\circ}$ lugar na predileção dos estudantes, após Biologia, Educação Física e História. O intuito de questionar a preferência da disciplina vincula-se ao interesse em identificar a proporção de estudantes nas ciências exatas, correlacionadas diretamente com a tecnologia e por tal, computação.

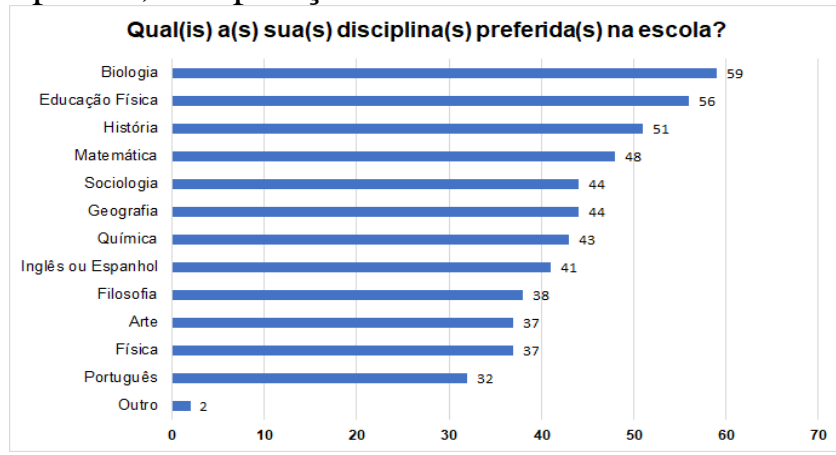

Figura 5. Disciplinas Preferidas

Na Figura 6 apresentam-se os cursos de graduação pelos quais os estudantes possuem interesse, as colunas que se encontram em destaque na cor vermelha são ofertadas pela Universidade do Estado de Santa Catarina, UDESC situada em Joinville. Dentre os entrevistados 25 estudantes não informaram sua escolha quanto a graduação. Verifica-se a variedade de escolhas dos estudantes, e o potencial de acolhimento do campus da UDESC para os alunos interessados.

Quanto a satisfação na realização das atividades desplugadas das cinco escolas que participaram das três propostas, foi questionado aos estudantes quais atividades gostaram e quais não gostaram, conforme a Figura 7. Sobre a atividade Decifrando a Mensagem 58 estudantes afirmaram que gostaram e 9 que não gostaram da atividade. Referente a atividade Colorindo os Números 48 estudantes responderam que gostaram e 18 que não gostaram. Na atividade Ordenação de Algoritmo 40 estudantes afirmaram que gostaram e 10 que não gostaram. Além disso, 25 estudantes afirmaram que gostaram de todas as atividades propostas. A partir destes resultados se percebeu que a quantidade de estudantes que gostaram da atividade Decifrando a Mensagem foi superior às demais realizadas. 


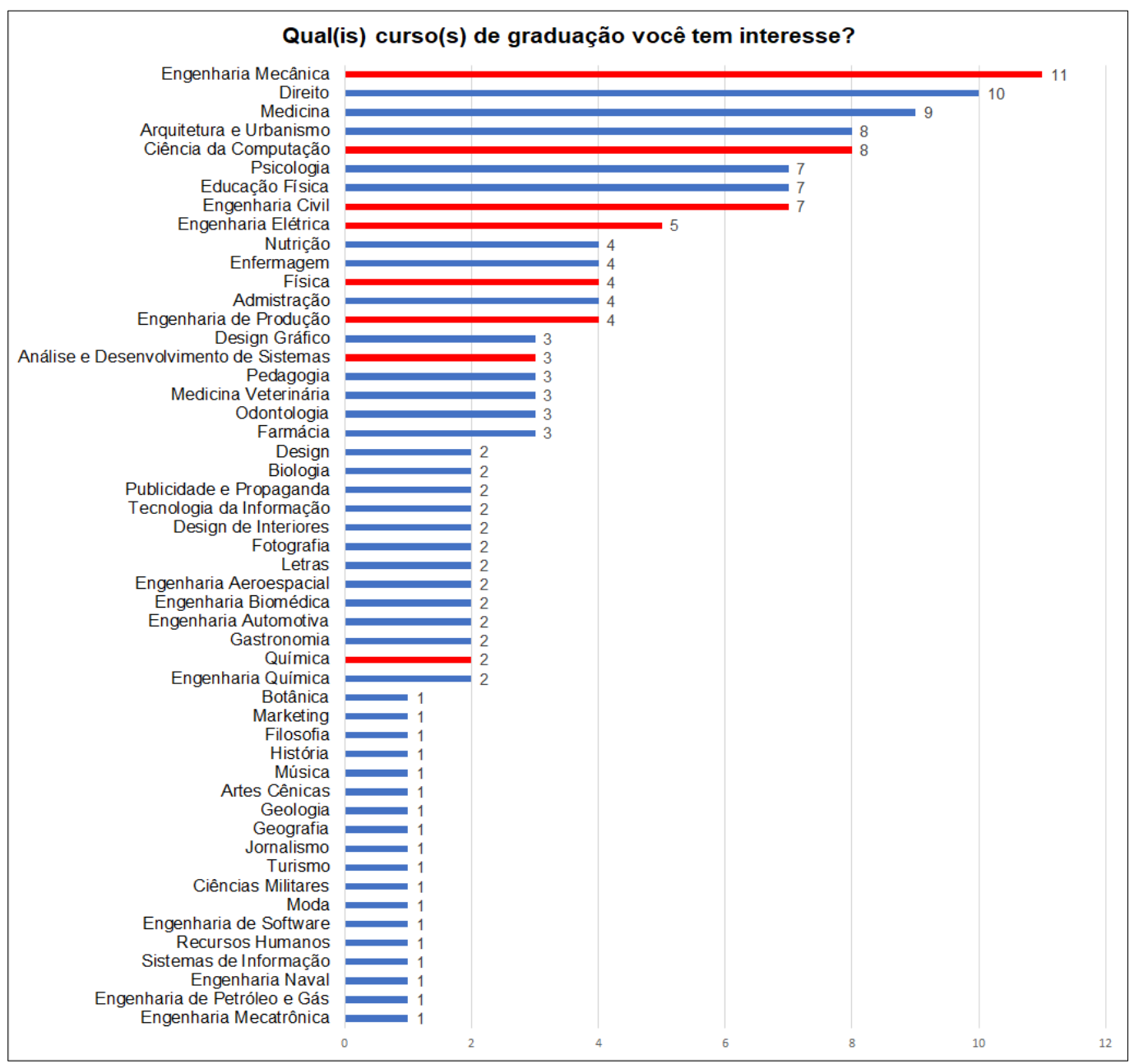

Figura 6. Cursos de Graduação pretendidos

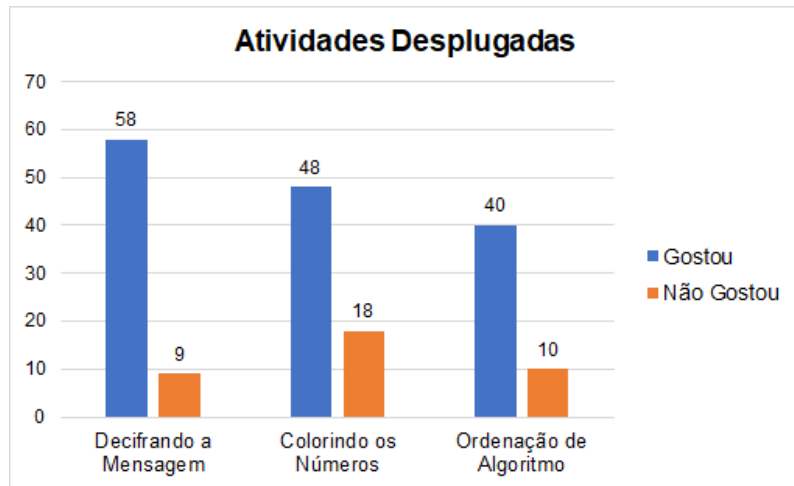

Figura 7. Percepção das atividades desplugadas vivenciadas

Na pergunta aberta realizada aos estudantes sobre se eles conseguiram associar as atividades experimentadas com a área de computação e em que momento, todos os estudantes responderam que sim. Em relação a quais atividades desplugadas, 28 alunos associaram com a atividade Colorindo os números; 24 estudantes com a atividade Decifrando a mensagem; 17 estudantes com a atividade Ordenação de algoritmos e 8 estudantes relacionaram com todas as atividades experimentadas, 4 não identificaram a relação e 23 não responderam. Alguns comentários foram: porque há mais de uma forma de realizar algumas atividades (algoritmo); se relaciona à criptografia de dados em trocar imagens por suas correspondentes letras; na decodificação do código; quando 
tentamos decifrar os códigos e os desenhos, principalmente com a associação da atividade com os pixels de imagens e através da lógica.

Em relação à questão: Sua visão sobre a computação com essa experiência ampliou? Descreva sua percepção. Do total, 15 alunos não responderam a questão, 35 alunos responderam de forma negativa, não ampliando sua visão e 39 estudantes responderam que sim, comentando que: tem coisas que nunca tinha visto; me interesso por essa área; pude perceber como funciona os pixels; agora sei como é formado as imagens no computador; pois estimula o raciocínio lógico; achei mais interessante; a criatividade; me deu vontade de ler mais sobre; com certeza tem muito por trás do computador; achei muito interessante; consegui associar a atividade com o comportamento do computador; permitiu associar o uso prático como teórico; muito é extremamente interessante ter o conhecimento de outras áreas das quais não estamos habituados.

Foi solicitado aos estudantes compartilharem sugestões, críticas ou elogios sobre as atividades, um total de 29 estudantes não responderam, 51 afirmaram que gostaram e colocaram palavras como: legal; criativas; motivadoras; interativas; dinâmicas; atrativas; empolgante; proporcionou trabalho em equipe; gostei, e 1 estudante sugeriu realizar atividades com nível mais complexo ou ainda aplicar estas atividades para estudantes mais novos.

\section{Discussão}

A avaliação realizada pelos estudantes, por meio do questionário de percepção de experiência aplicado ao final das atividades desplugadas, mostrou que os objetivos da proposta foram alcançados durante o percurso. Os estudantes demonstraram interesse pelas atividades propostas, sendo possível observar colaboração entre as equipes e dedicação na realização. Diante das atividades desplugadas aplicadas se evidenciou que a computação está presente em nosso cotidiano, como por exemplo, na sequência de passos de um algoritmo para fritar um ovo.

Com base no Quadro 1, no tempo estimado para a realização das atividades propostas, somente a primeira escola da rede estadual excedeu o tempo, obtendo resultado $\mathrm{t}=13,6 \mathrm{~min}$, sendo que o tempo previsto para conclusão das três atividades era de 12 minutos. A escola com melhor desempenho no tempo de realização foi a da rede particular 6 onde $\mathrm{t}=6,8 \mathrm{~min}$.

\section{Considerações Finais}

Neste trabalho foi descrito um relato de experiência no UPA baseado na aplicação de atividades de Computação Desplugada realizado com estudantes do Ensino Médio de escolas públicas e privadas, tendo por objetivo inserir os fundamentos da ciência da computação e motivar os estudantes a ingressarem nos cursos da área de exatas na universidade.

O relato do experimento corrobora com a ideia de que a Ciência da Computação possui diferentes meios dos quais pode contribuir no processo de ensino e aprendizagem, e que por meio da Computação Desplugada e do Pensamento Computacional é possível desenvolver habilidades de resolução de problemas e raciocínio lógico dos estudantes. Além disso, nas atividades propostas foi possível explorar o trabalho em equipe e colaborativo e observar a habilidade e criatividade de cada grupo no cumprimento das tarefas.

Por meio da análise dos questionários de percepção de experiência individual respondidos pelos estudantes foi constatado que todos gostaram de participar das atividades propostas, sendo que todos participaram das atividades em grupos. 
Uma limitação encontrada no desenvolvimento das atividades desplugadas para o evento foi a questão do curto espaço de tempo para aplicação, para isto, o planejamento e teste piloto das atividades foram criteriosamente estudados. Embora o tempo para execução tenha sido curto, foi possível que os estudantes desenvolvessem as atividades propostas relacionando aos conceitos da ciência da computação abordados. Como trabalho futuro objetiva-se investigar e preparar novas estratégias da Computação Desplugada para aplicação com estudantes do Ensino Médio, para que possam experimentar novas atividades e desafios de forma lúdica e colaborativa, conhecendo novos conceitos da área da ciência da computação.

Agradecimentos: Este trabalho foi realizado com apoio do Programa de Bolsas de Monitoria de Pós-Graduação-PROMOP da UDESC. Agradecemos o apoio financeiro da FAPESC, Edital FAPESC/CNPQ Nº6/2016, T.O. Nº:2017TR1755 -Ambientes Inteligentes Educacionais com Integração de Técnicas Learning Analytics e Gamificação e FAPESC N ${ }^{\circ}$ 04/2018 apoio à infraestrutura para grupos de pesquisa da UDESC - Termo de Outorga ${ }^{\circ} \mathrm{N}^{\circ}$ : 2019 TR585.

\section{Referências}

ALVES, Francisco Cordeiro. (2001) Diário: um contributo para o desenvolvimento profissional dos professores e estudo dos seus dilemas. Educação, Ciência e Tecnologia, p.222239. Disponível em: <http://twixar.me/sdJn>. Acesso em: 27 maio 2019.

ASCENCIO, Ana Fernanda Gomes; CAMPOS, Edilene Aparecida Veneruchi de. Fundamentos da Programação de Computadores. São Paulo: Pearson Prentice Hall, 2005.

BARRETO, Luciano Porto (Org.) (2011). Ensinando Ciência da Computação sem o uso do computador. Bahia: FAPESB, 113 p. Disponível em: <https://bit.ly/2HM2P1p>. Acesso em: 18 out. 2018.

BELL, T., WITTEN, I, H., FELLOWS M. (2011). Computer Science Unplugged: Ensinando Ciência da Computação sem o uso do computador. Tradução coordenada por Luciano Porto Barreto.

BEZERRA, Fábio. Bem mais que os Bits da Computação Desplugada. (2014). III Congresso Brasileiro de Informática na Educação (CBIE). 20ª Workshop de Informática na Escola.

BLIKSTEIN, Paulo. (2008) "O Pensamento Computacional e a Reinvenção do Computador na Educação”. Disponível em: <http://bit.ly/1lXlbNn>. Acesso em: 26 maio 2019.

BORDINI, Adriana et al. Computação na Educação Básica no Brasil: o Estado da Arte. Informática Teórica e Aplicada, Porto Alegre, v. 23, n. 2, p.210-238, 2016. Disponível em: <encurtador.com.br/aeJQR>. Acesso em: 07 jun. 2019.

CAVALCANTE, André L. B.. Teoria dos Números e Criptografia. Revista Informática, p.17, 2005. Disponível em: <http://twixar.me/7dJn>. Acesso em: 05 maio 2019.

MANHÃES, T. S.; GONÇALVES, F. S.; CAFEZEIRO, I. Computação Desplugada e Educada. VII Esocite, p.1-25, 2017.

MARTINHAGO, Adriana Z. et al. (2014) Computação Desplugada no Ensino de Bancos de Dados na Educação Superior. XXXIV Congresso da Sociedade Brasileira de Computação, p.1307-1315. Disponível em: <encurtador.com.br/hDES6>. Acesso em: 01 jun. 2019.

SILVA, Thiago Reis da et al. (2014). Oficinas Itinerantes de Scratch e Computação Desplugada para Professores como apoio ao Ensino de Computação: um Relato de Experiência. WIE, Dourados, p.380-389. Disponível em: <encurtador.com.br/lntu8>. Acesso em: 07 jun. 2019.

VIEIRA, Anacilia; PASSOS, Odette; BARRETO, Raimundo (2013). Um Relato de Experiência do Uso da Técnica Computação Desplugada. WEI, p. 671-680. SI. Disponível em: $<$ https://bit.ly/2Qlw54b>. Acesso em: 12 out. 2018.

V. $17 \mathrm{~N}^{\circ}$ 3, dezembro, 2019 RENOTE DOI: 